\title{
What is the heartland of psychiatry?
}

\author{
GUY M. GOODWIN and JOHN R. GEDDES
}

\begin{abstract}
Summary Psychiatry haslong identified schizophrenia as its defining disorder, its heartland as it has been called. In the past 20 years, this has had a number of negative consequences for psychiatry as a medical specialty, which result from the uncertainty of diagnosis and an increasing emphasis on demedicalising services in an attempt to provide social care outside hospital. These changes have probably increased the stigma attached to psychiatric practice and threaten to deskill doctors. They have also meant that services for other disorders do not meet the needs of patients. To continue to allow schizophrenia to be the paradigm condition is against the interests of psychiatrists and their patients.
\end{abstract}

\section{Declaration of interest Both} authors have received financial support from pharmaceutical companies. G.M.G. is a non-executive director of the Oxfordshire and Buckinghamshire NHS Mental Health PartnershipTrust.

About 20 years ago, it was a commonplace to refer to schizophrenia as the heartland of psychiatry (see Bebbington \& McGuffin, 1988). The reason for this curious use of an emotive reference to territory seemed rather odd, but not terribly important, because it was in many ways an exciting time to do research in psychiatry or have a scientific interest in its progress and understanding. Unfortunately, the identification of schizophrenia in this way has had largely negative consequences for the practice of psychiatry as a distinctive medical specialty, the full effects of which are only fully being felt now.

\section{WHY SCHIZOPHRENIA?}

Why was schizophrenia so important to the generation that looked to Aubrey Lewis, John Wing, Bob Kendell and others for leadership? It had a lot to do with diagnosis, and perhaps with beds. Schizophenia's rich phenomenology and arcane foreign language literature made its diagnosis seem difficult and interesting. Moreover, making the diagnosis of schizophrenia came to seem very important because psychotherapists had indulged in an almost unlimited extension of the 'schizophrenia' concept in 1950s' America, to include most neurotic problems. The US-UK collaborative diagnostic project probably marked the highpoint of confidence and international influence of British psychiatry (Kendell et al, 1971); its focus effectively defined what psychiatry was. It established that psychiatrists could reliably play by operational rules in making a diagnosis and led directly to the DSM and ICD classifications. Furthermore, schizophrenia was restored as a core disorder that trumped other diagnoses in a notional hierarchy of importance. This was fundamental. The prevailing view was that schizophrenia could be reliably recognised on the basis of symptoms such as thought insertion. Thought insertion was taken to have the property that Jaspers required of a true delusion: it can be traced back to an 'irreducible and non-understandable experience' (Wing, 1978). It is not an extreme experience of a normal kind. When dominated by such phenomena, a mental state is thus qualitatively different from the normal. Finally, despite appearances to the contrary (comorbid anxiety, depression, mood elevation and cognitive impairment were commonly present), schizophrenia was held to be a unitary diagnosis. Just how unreasonable this was, and remains, seems still to be poorly appreciated.

The first and most obvious problem was that an emphasis on diagnosis delivered psychiatrists into very uncomfortable arguments about the status of schizophrenia. To suppose a qualitatively abnormal mental state is, first, foremost and inevitably, stigmatising. It echoes the sane/insane legal distinction and to this day many psychiatrists are reluctant to tell their patients that their diagnosis is schizophrenia. Second, it throws up a boundary problem: however confident one may be about its more severe forms, schizophrenia has rather friable edges, and the diagnosis at its most friable too often hinges on what people say they do and do not believe, and might or might not do on the basis of such belief. A clinical diagnosis of schizophrenia could, when based on partial delusions alone, be a social construct and the antipsychiatry argument, in all its pompous certainty, proceeds from that. Finally, patients frequently disagree with the psychiatrist's interpretation of their mental state, and may have to be detained against their will. Historically, English psychiatrists have probably been too enmeshed in the workings of the Mental Health Act and their diagnosis has been too central in deciding detention of patients with schizophrenia. This is rarely the best basis for a positive therapeutic alliance. So, by clinging to schizophrenia as a heartland, psychiatrists have helped define and strengthen the negative view others have, both of psychiatry and of themselves.

Then there was the matter of beds. The system of large asylums may have originally been a humane innovation, but by the 1960s it had come to be an increasing cause for scandal. The institutions mirrored the chronicity of schizophrenia and seemed to amplify rather than correct the disabilities in everyday living that so many sufferers experience. Far too many patients languished in long-stay beds with minimal dignity and very little medical attention. However, the reaffirmation of the status of schizophrenia seemed to impede rather than facilitate the creation of really new services, as radicals of the time such as William Sargant had argued were needed in general hospitals to treat affective disorder (see Sargant, 1967). Possession of beds was also a perverse measure of a doctor's individual power within the existing administrative structure, and the mentality of many psychiatrists was undeniably too hospital orientated. So, although the possession of some in-patient beds for acute treatment or respite remained and remains essential for good care, there was a failure 
to distinguish between this need and the cushion of longer-stay facilities.

\section{MODERNITY: SCHIZOPHRENIA PLUS SOCIOLOGY}

The shape of the 'modern' psychiatric service has, therefore, been defined as much by what it was against, as by what it was for. As a corrective to the hospital-based treatment of schizophrenia, there had to be a transfer of resources away from in-patient services. Although this was reasonable in the age of the physically remote asylum, it has continued well after longstay beds have disappeared, with predictably dire consequences for the quality of acute in-patient care. Moreover, avoiding hospital admission irrespective of illness outcome has, almost unthinkingly, become an objective for psychiatric services - and highly inappropriate if the patient actually needs hospital care.

Just as beds defined what was to be avoided, so the emphasis on diagnosis has acquired an unwanted flavour. The problems that patients with schizophrenia face were reformulated as 'social'. So what the patients need is 'social care'; this remains the Department of Health's 'big idea' for the future of psychiatry and the sociologically correct answers were formulated in the National Service Framework for Mental Health (Department of Health, 1999). This formalised and extended in a surprisingly concrete way the services required for severe mental illness in England. Psychiatrists were notable only by their exclusion from the process whereby the Framework was developed. Bipolar disorder was not mentioned at all, and the National Service Framework, largely unmodified, remains the dogmatic top-down blueprint against which targets managers continue to measure themselves today. The idea that there might be specific conditions that require specific effective treatments obviously echoes in a ghostly way through proliferating guidance from the National Institute for Health and Clinical Excellence (NICE), but something is lost in translation to the block contract of psychiatric care. The policy guarantees only a mass of non-specific caring measures for people whose severity of 'mental health problem' is largely measured by their disinclination to engage with the services provided.

\section{AN ALTERNATIVE PERSPECTIVE}

Might things have been different? Bipolar disorder was usually misdiagnosed as schizophrenia before it was also rescued from the diagnostic shambles by the USUK collaborative diagnostic project. What if it had been the dominant paradigm the heartland condition? Bipolar disorder is no less debilitating, on comparable measures of morbidity and mortality, than schizophrenia (Clement et al, 2003) and is much more common. Moreover, in almost every respect it would have afforded psychiatry a model within which the medical role is easier to define. The development of this model could have informed psychiatric services in general with a greater balance between medical, psychological and social care.

First, the diagnosis of bipolar I disorder characterised by mania is largely uncontroversial because it is based on observable and obvious changes in behaviour. At least, we have yet to hear anyone claim that mania does not exist. Second, bipolar disorder is, exactly like schizophrenia, a complex phenotype that can include virtually all the key phenomenological entities we recognise in psychiatry-depression, mania, psychosis, anxiety, substance misuse, cognitive impairment, neuroendocrine abnormality, sleep disturbance and distinctively variable illness course. The difference is that we do not pretend otherwise, and the fact that these apparently independent dimensions cluster within the single diagnosis of bipolar disorder is accepted as very challenging. Does it mean that the dimensions are themselves related to each other and severity in one will entail severity in the other-perhaps because of common developmental variations in biology or the cumulative effects of illness? Or are cases of bipolar disorder simply represented by those people who sit on the wrong end of these multiple domains, all of which can behave relatively independently? Can diagnosis usefully continue to be categorical without measuring the dimensions that characterise the disease? These are interesting questions that could also reasonably be asked of schizophrenia, but seldom are. Finally, we are not embarrassed to tell patients they have bipolar disorder. They are often grateful to have a diagnosis that explains more than it obscures.

There are other contrasts with the schizophrenia model which are equally important to clinical practice. The course of illness in bipolar disorder allows a much more meaningful distinction between the needs of patients for sympathetic in-patient respite care when acutely ill and for outpatient-based interventions when comparatively well. The treatment of bipolar disorder is also much less amenable to one-size-fits-all social care, which, like most such provision for dependent groups, tends with time and inattention more to reflect the needs of staff than patients: staff become rather more willing to assess patients' needs than to try and satisfy them. Bipolar disorder is more likely to challenge clinicians to understand the illness and its treatment in relation to individual and autonomous patients.

Finally, treatment of bipolar disorder demonstrably requires the medical expertise which we should take a pride in. The medications that we have available seem often to require use in combination, which probably reflects the complexity of the phenotype. Therefore, prescribing for patients with bipolar disorder requires knowledge, skill and experience. We make a distinction between acute and long-term medication and seek active involvement by patients in managing acute exacerbations of symptoms. Psychological treatments complement the medical approach, and enhanced care is an objective for all patients (Goodwin, 2003). Psychological interventions can reduce the risk of relapse when added to treatment as usual, and have a pragmatic emphasis on self-monitoring, self-management and education about the illness. Moreover, the indication for the content and the timing of treatment is being rationally defined and refined in controlled trials (Vieta \& Colom, 2004). The confusion around whether cognitive-behavioural therapy (CBT) is really useful for schizophrenia is telling (Turkington \& McKenna, 2003; Durham et al, 2005). Moreover, although being adopted by NICE, as one might say, for the nation, the relevance of CBT for psychosis has been wildly amplified at grass roots level in a way that could never have occurred for bipolar disorder common sense would prevail when the greatest therapeutic optimist met their first patient with florid mania.

\section{DO PSYCHIATRISTS HAVE A FUTURE AS MEDICAL SPECIALISTS?}

These differences illustrate what can occur in psychiatry when modern medical treatments 
are allowed to develop unhampered by ideology, compared with what happens when they are not. The social model of schizophrenia was the minority, left-wing, 'show biz' cause of the 1960s, a formative time for our late-middle-aged policy makers, who have their own curious heartlands. Its current dominance is neither measured, nor moderate. Its essentially totalitarian spirit has even required a new language - an Orwellian 'newspeak' where no one must be said to have an illness, comply with treatment or be a patient. The only possible surprise is that the use of the word schizophrenia has not yet been banned from the National Health Service.

Other losses have been more subtle. Can it be sensible to invest a tenth of what we do on schizophrenia on research in bipolar disorder (Neurosciences and Mental Health Board Strategy and Portfolio Overview Group, 2005)? Why do so many junior doctors leave psychiatry because of the role it currently offers them (Lambert et al, 2006)? Most doctors may feel marginalised by managers with regard to resource allocation: psychiatry appears to us unusual in the extent to which managers literally think they know how we should do our jobs. Doctors have a training that brings scientific rigour to what they observe and how they treat. As doctors we also have a broader base in general medicine than most other disciplines involved in psychiatry. A good doctor must be able to make a difference to an individual patient. However, our assumptions and allegiances - our heartland-must be fruitful, not a barren wilderness of good intentions.

GUY M. GOODWIN, DPhil, FRCPsych, FMedSci, JOHN R. GEDDES, MD, FRCPsych, University Department of Psychiatry, Warneford Hospital, Oxford, UK

Correspondence: Dr Guy M. Goodwin, University Department of Psychiatry, Warneford Hospital, Oxford OX37JX,UK.Email: guy.goodwin@psych.ox.ac.uk

(First received 29 January 2007, final revision 23 March 2007, accepted 5 April 2007)

We could still develop a more interesting role for doctors in psychiatry because there are effective evidence-based treatments for a wide range of specific conditions, not just bipolar disorder. We happen to know bipolar disorder best and we have been appalled by the difficulties faced by people with bipolar disorder in the current model of secondary services. However, little seems likely to change if schizophrenia continues to occupy such a central and distorting position in our thinking. Why should one condition continue to be so dominant? In general medicine, it would seem ludicrous if the decision was made by the Department of Health to restructure all care around the model of diabetes. To continue to make schizophrenia the paradigm condition in psychiatry is against the interests of psychiatrists and, more importantly, of our patients.

\section{REFERENCES}

Bebbington, P. \& McGuffin, P. (1988) Schizophrenia: The Major Issues. Heinemann \& Mental Health Foundation.

Clement, S., Singh, S. P. \& Burns, T. (2003) Status of bipolar disorder research: bibliometric study. British Journal of Psychiatry, 182, 148-152.
Department of Health (1999) National Service Framework for Mental Health: Modern Standards and Service Models. Department of Health.

Durham, R. C., Chambers, J. A., Power, K. G., et al (2005) Long-term outcome of cognitive behaviour therapy clinical trials in central Scotland. Health Technology Assessment, 9, I-174.

Kendell, R. E., Cooper, J. E., Gourlay, A. J., et al (197I) Diagnostic criteria of American and British psychiatrists. Archives of General Psychiatry, 25, 123-131.

Goodwin, G. M. (2003) Evidence-based guidelines for treating bipolar disorder: recommendations from the British Association for Psychopharmacology. Journal of Psychopharmacology, 17, 149-173.

Lambert, T. W., Turner, G., Fazel, S., et al (2006)

Reasons why some UK medical graduates who initially choose psychiatry do not pursue it as a long-term career. Psychological Medicine, 36, 679-684.

Neurosciences and Mental Health Board Strategy and Portfolio Overview Group (2005) NMHB Mental Health Scoping Study. http: / /www.mrc.ac.uk/Utilities / Documentrecord/index.htm?d=MRC00I79|

Sargant, W. (1967) The Unquiet Mind - An Autobiography. Heinemann

Turkington, D. \& McKenna, P. J. (2003) Is cognitivebehavioural therapy a worthwhile treatment for psychosis? British Journal of Psychiatry, 182, 477-479.

Vieta, E. \& Colom, F. (2004) Psychological interventions in bipolar disorder: from wishful thinking to an evidence-based approach. Acta Psychiatrica Scandinavica Supplementum, 422, 34-38.

Wing, J. K. (1978) Reasoning About Madness. Oxford University Press. 